\title{
Camphor Laurel: A Re-vision of Desire
}

\author{
Kate McInally
}

$\mathrm{T}$ he consolidation of the genre of Young Adult fiction in Australia has enlivened a space in which to look at representations of sexuality within the larger sphere of children's literature. Many productive discussions of gender, both in fiction and in the varied theoretical perspectives that are applied to it, have encouraged deconstructive readings that recognise the heterosexist nature of much mainstream fiction. The naturalisation of heterosexuality silences the voices of those characters (and readers) that do not 'fit' into an (often assumed) heterosexual identity. A small percentage of texts address this bias and offer alternative models of sexuality. Young Adult literature, then, potentially offers a diverse and extensive textual domain in which to theorise the representations of sexuality and gender.

The field of Young Adult literature evidences a shift in its representation of diverse sexualities and in the diverse narrative modes which it deploys. However, the genre has not shown itself to embrace any significant shift from the discourse of maturation as central to the construction of the young adult character. In YA fiction, the representation of teenage protagonists is arguably obsessed with ideas about identity built on theories of psychosexual development. This framework needs to be questioned, however, because the accepted model of development and maturation encourages the construction of only two subject positions in text; either the implied heterosexual character (and reader) or one based on identity politics, that is resolved, most often, through 'coming out' and declaring an alternative but equally fixed sexual orientation. This is often implicit rather than stated in the resolution of the novel.

The problem with reinforcing this developmental model in fiction is that it largely ignores the very intense, and often passionate bonds between young girls, preferring to categorise these intensities as 'crushes' that are 'quite normal' but are simply a phase in a progression to a heterosexual maturity. This idea of progression to maturity demonstrates a cross-disciplinary acceptance of a developmental model built around categorisation and taxonomisation of subjectivity, and one in which the power relationships between adults and children remain unquestioned. Further, when girls'relationships and desires are categorised, in this case as phases of development, they are also delegitimised. Desire and passion between girls becomes simply a step on the road to 'real' sexual orientation (most often represented as heterosexual), and the constructed idea of the normative.

Sarah Walker's novel, Camphor Laurel (1998), however, goes some way to offering an alternative view of possible subject positions in relation to desire and the concept of maturation. Rather than privileging a notion of desire that is bounded by any 'self', the text posits desire as unable to be channelled by patriarchal discourses of psychosexual development, particularly psychoanalytic theory. Instead, it relies on a perspective of empowered feminine desire that is without boundaries - one which flows between distinctions of friendships and sexuality, notions of truth and reality, and circulates, instead, in a space that is arguably between pre-oedipal imagery and Jacques Lacan's psychoanalytical theories of the Symbolic. Desire is unable to be contained in this text, or ordered into any concept of the 'normative'.

'Feminine', then, in this paper, will be a term with a designated meaning. It expresses a desire that is unable to be subsumed into the Symbolic order. It has no subject to which it belongs - no fixed foundation in 'woman' or 'girl'. It is a desire, rather, that is outside the patriarchal ordering of expression through language. This coding of the feminine is expressed in the work of the French feminists, Cixous, Kristeva and Irigaray, who question how feminine desire can be expressed within a patriarchal system, and if there are alternative modes of expression that reside outside Lacan's 'Law of the Father', the ordered world structured through language which silences the feminine.

Camphor Laurel engages with male-centered discourses that have attempted to reconcile feminine desire with sexual orientation and categorisation. Through a recreation of these discourses, the text unmasks the proximity of the perverse (shifting desire, jealousy and secrets), to the normative (friendships, maturity and development). Ultimately, Walker's text remains hopeful —not in a rejection of these narratives, or an inversion of their binaries, but in an attempt to recreate them.

Walker's text centres on the shifting friendship of two girls, Melissa and Julietta. The characters face continual threats to their relationship. Their parents, for example, 
attempt to forbid any contact between them due to the physicality of their relationship, which involves sleeping in the same bed (p.46) and dancing closely together (p.45). As teenagers they predictably disobey these rules. However the text does not fall back on the discourse of adolescence as a time of rebellion. Its focus, instead, is on the importance of connection between these young girls, and the resistance they encounter in the rules and language of western patriarchy.

The narrative constructs characters that resist being 'read' Melissa, the shy, lonely protagonist, embodies a space between love for, and obsession with her first friend Julietta. An awkward character, she is 'chosen' by the beautiful Julietta who is an amalgam of literary versions of the feminine - the seductress, the innocent, the knowing, the helpless, the perfect and the flawed. The characters' friendship parallels their desires which are concurrently the same and different. Both girls desire an intimacy that allows them an escape from the ordered existence of what is acceptable and what is normal for young girls, which the text celebrates in the way they dance: 'Julietta takes Melissa's hand and tugs...pulls her closer and sways. Their foreheads press together and the music takes them away. The music and Julietta's pelvis.' And yet difference is established in the text to complicate notions of feminine desire as leading to a fixed orientation or identity. Julietta craves new experience, an otherness or other way of living that necessarily challenges the options made available to her in western patriarchal culture; she wants to travel to exotic, unknown places like Morocco, Vietnam and Peru (p.57). Melissa, on the other hand, fears otherness because of the potential dangers she senses within it. Her dreams of a future are confined to western cites of knowable substance: Paris, Los Angeles and London (p.57), and she is 'afraid of the future' (p.58). Sameness and difference are established as a desire that circulates between them as need, as comfort, as friendship and as sexual excitement. This space of the between, "between things, between points... belongs to a smooth space" (Deleuze \& Guattari 1988, p.505), a space where they 'calmly maintain silence' (p. 29) and where they are not subjected to patriarchal discourse relentlessly attempting to define them.

A third character adds the depth and complexity that fleshes out discussions of sexuality in the novel. Ursula acts as the completion of the triad, foreshadowed in the imagery of Julietta's 'fair haired leg bent like a triangle' early in the text (p.14). Ursula provides a textual alternative to the bonds of two (ways of being). Her character not only disrupts the notions of two available subject positions (assumed heterosexuality or the narrative of 'coming out') but also links rather than splits the usual distinctions between friendship and sexual desire in representations of girl's relationships. When Melissa and Ursula 'regard each other with interest' (p.147) after Melissa has spent 'hours looking into Ursula's (eyes) (p.147), the text sets up a questioning of the representation of girls' intimacies and relationships.

The importance of the inclusion of this character in the text is not only that it enables multiple points of view in relation to the character of Julietta, but rather, that the figure of Ursula allows ideas about the normative to be questioned. The normative split between friendship and sexuality is opened up and illustrates that 'normal', even when one positions homosexual or lesbian relations within it, is a patriarchal discursive construct. The text rejects this discourse, through the characters' rejection of the language that contains it. Melissa and Ursula 'don't speak much' (p.147); it is a closeness that cannot be expressed. This rejection of language also rejects the construct of the normal, especially in regard to desire. Further, when the girls' communication is shown to exist outside the structure of language, the text rejects the idea that the construction of subjectivity necessarily entails a developmental psychosexual progression.

Camphor Laurel, then, can be read through, and at the same time as a resistance to, the phallocentric discourse of psychoanalysis, articulated through the work of Jacques Lacan. Read in this way, it interrogates the notion of developmentalism, which describes a progression toward maturity, the normative and sexual categorisation. Equally, the notions of truth and reality become fluid constructs that undermine fixed positions of sexual subjectivity.

Although Lacan's theories of subjectivity, like Freud's before him, have been reworked by feminist theorists to attend to the relative lack of attention and agency given to the female subject (Rowley and Grosz 1990, p.175), his 
central thesis insists that in order to gain subjectivity, the child must enter into the Symbolic order, a psychological territory ruled by the 'Law of the Father'. This realm is constituted through language, and is accessible to the child through a split with the maternal realm (the Imaginary). The entry into the Symbolic entails a negotiation of "the mirror stage', where the child distinguishes itself through acknowledging what is not 'I'. Because subjectivity is gained through a premature loss of what the child can never regain - the sense of wholeness before the split - the subject remains permanently in a state of desire for what is forever lost. The child, in recognising an image as itself, then makes "an "identification" in the "mirror" (Lacan 1966, p.2). This is made up of the other image, as well as the self, so that the subject is one that is formed through, and maintains, this split. Because this subjectivity is gained through language, and language and meanings are unable to be fixed, then the subject, too, can never be complete; subjectivity remains in a state of becoming. Yet 'becoming' is located within the patriarchically ordered world, and relies on subject positions related to desire. This desire is based on lack; it is a negative desire, one that can never be fulfilled.

This brief sketch of Lacanian theory might be seen to provide a framework for the text of Camphor Laurel, yet the text remains in a state of play with Lacanian theory. It does this by reordering Lacan's psychosexual developmental stages. The mirror stage in Camphor Laurel occurs on the last page of the text, yet the characters are already invested with desire. The imagery of the language provides the unspeakable pleasure that the characters find in each other:

(Melissa) sits on the sand [no towel] and glares at Julietta's white bottom bounding into the surf. It's hot. Hot on the beach. It's very hot. Melissa melts. The ice-cream in her stomach is curdled warm milk. She fades, she glowers, she rouses herself. Her bikini drops on the sand in a whisper of dead skin. With an ice-on-hot body yelp, she joins Julietta in the green waves...Shivering, glossy otters.

(p.22).

Melissa's desire, here, is to take pleasure in the extremes of the relationship she has with Julietta, written through her physical sensations of heat and ice, curdled milk and the shedding of dead skin. Her desire for Julietta is further established in the narrative when she describes the importance of her relationship as 'I want this too much' (p.44). This intense desire is an impossibility in Lacanian theory because desire does not appear until after the mirror stage when the unconscious is formed, bringing with it subjectivity. The text's reordering of Lacanian stages recognises the young girl's intense and desirous relationships that are under-represented in fiction. It also reinforces fluidity rather than fixed subject positions. The conclusion of the text, where 'things look normal but aren't' (p.156), becomes a way to subvert a developmental model in which heterosexual relationships are privileged over friendships, desire or shifting sexualities. This is not an inversion, but a retelling of the male-centered narrative of psychoanalysis. The text changes the focus through emphasis rather than inversion. The text, itself, reveals this point in relation to the flux of meaning inherent in language: 'Julietta followed me. Julietta followed me. Julietta followed me. She puts the emphasis in particular places' (p.8, original emphasis).

The Lacanian framework, which posits the unconscious as a structure like language, and made through language, is established early in the novel. Specifically, Lacan explains that the same signifier may have different signifieds, so that 'we are forced to accept the notion of an incessant sliding of the signified under the signifier' (Lacan 1966, p.154). This is evident in Camphor Laurel particularly during Melissa's discussion with her mother, who describes Julietta as 'worldly'(p.7). Melissa looks up the word in the dictionary, and chooses one meaning from the two given, that of 'sophisticated'. When she discusses this with her mother, however, the lack of fixity of meaning becomes apparent. Her mother insists that there is a subtle difference between 'worldly' and 'sophisticated'. Yet, Melissa doesn't know what her mother's words 'a subtle difference' refer to, since at the time her mother is painting a chair, and the same phrase 'a subtle difference' may also be referring to the colour of the paint that she is using. When Melissa attempts to clarify this, her mother explains that there is a difference 'between what a word means and what it really means' (p.7). This use of metaphor in the paint and metonymy in the displacement of meaning establishes the 
Lacanian framework (Lacan 1966, p.156). Melissa and her mother find these linguistic puzzles tortuous. But while Melissa's mother refuses to question the realm of Lacan's Symbolic, Melissa continues to subvert the linguistic structure by 'torturing (herself) with questions' (p.8). Rather than metaphor occurring 'at the precise point at which sense emerges from non-sense' (Lacan 1966, p.158), the text proposes that sense (through language) is restrictive and limiting to feminine sexual subjectivity.

The text continues to play with the theory of subjectivity as dependent on an entry into Symbolic language, when Melissa and Julietta meet boys who are riding trail-bikes. Melissa's experience with the boy and the motorbike works as a parody of patriarchal, masculinist language. Whilst riding, the boy, 'older than the rest...talks the whole time' (p.16). He says, 'SeehowIchange-intofirstgearlikethisnowsecondbutyougotta-giveitsomethrottle" (p.16). Melissa 'doesn't listen' and instead reveals that her desire is only for Julietta (p.16). In this way the text contests the very basis of psychoanalytic theory, which posits women's unconscious as formed through and because of the existing 'Law of the Father'. This is a system of language that is shown to have little relevance to Melissa's desire. It is the proximate, the bike rider, who enables Melissa to construct herself as the object of Julietta's gaze, which again blurs the boundaries between same-sex and heterosexual desire, and implicates one in the other.

The text also counterpoints Lacanian theory in its use of the doppelganger, or the double. The double, in Camphor Laurel, represents the split subject, which, as we have seen, occurs after the mirror stage, when the child begins to enter the Symbolic and thus attain subjectivity. Lacan explains that we can 'observe the role of the mirror apparatus in the appearances of the double, in which psychical realities... are manifested' (Lacan 1966, p.3). The double in this text is constructed through Melissa and Julietta on the first page of the text. Melissa 'knows what it is like to lose half of what you have and still become whole' (p.1), through her relationship with Julietta. Robyn McCallum discusses the relationship of Lacanian theory to the use of the doppelganger in Australian Young Adult fiction, and argues that it allows a reading of constructed subjectivity (McCallum 1999, pp.67-98). She describes the double in fiction as "the situation in which a character has an imagined or real counterpart or twin who is either a mirror inversion or a duplicate of that character and whose presence is crucial for that character's sense of identity' (McCallum 1996, p.17). The double is established in the text through a mirror inversion between Julietta and Melissa, but it is important to distinguish this from a binary inversion. The text does not use the mirror inversion as an attempt to bring high what is low (one of Derrida's steps in deconstruction), but instead, to dispense with binary divisions (as Derrida would have it) and illustrate that what is seen as opposites are part of the same, and dependent on each other. This is constructed through physical descriptions: Julietta is 'tall, cream-skinned and self assured' (p.2), while Melissa is 'dark and surly, awkward and clump-footed and not at all like Julietta' (p.4). Yet, the text dispenses with the dark/fair binary, through Julietta's words 'maybe you looked like my twin' (p.3).

The significance of the text's refusal to invert binary oppositions, dispensing with them through looking at the interrelationships of terms, is that western binary thought has been integral to the maintenance of categorisation, taxonomization and classification in western theories regarding subjectivity and sexuality. In terms of young adult sexuality the addition of categories of bisexual, transsexual, transgender and so on, work to leave the homo/hetero binary as central, with 'other' sexualities reinforcing it. This works to create stronger margins that hold the centre in place. In the text's attempt to 'twin' or implicate oppositions as within each other, the binary loses its struggle to keep sexuality taxonomised. Sexuality, instead, becomes more like the Deleuzean model of flows, not owned by any prior body, but as a creative force-changing, mutating even, with every connection that is made (Deleuze and Guattari 1988, p.406). This allows Melissa a wider appreciation of what Julietta has become to her. Connections allow Melissa to appreciate more than Julietta's perfection (p.19), and see her as 'ordinary and tragic...(and) beautiful' (p.154). Melissa's desire is not restricted only to Julietta, however. At the swimming pool Melissa's desire connects to boy's bodies as well;

She likes the cocky-comb of wet strands flipping up from their foreheads. She likes the vulnerable belly 
buttons and sore, blinking eyes. She likes soggy lashes as if they've been crying, and streams that run off chins. She likes goosebumps, brown boynipples and creamy-white bottoms under elastic. (p.71).

Melissa acknowledges these desires, but rejects the channelling of them into patriarchally ordered categories, revealed when she 'doesn't want to talk to them' (p. 71). In this text the Symbolic, the order of language which posits desire as lack, is rejected. Instead, desire is fluid like the droplets of water that make the boy's body so attractive to her.

The Lacanian double reappears in the text through shared narrative, where the individual voices, at times, become almost indistinct:

'Do you believe in life after death?' (absolutely)

'Do you believe in God?'

(sometimes)

In this passage of dialogue it is unclear which of the girls is speaking. This ambiguousness is central to the dissolution of boundaries between them. Melissa is aware of this connection illustrated in the dialogue, so the text at this point has her focalize precisely what is at stake: "Melissa doesn't want to push the boundaries, in case they break and her only friend leaks away" (p.4). Through this description the text illustrates that boundaries, constructed by the double, are fluid. It illustrates at the same time, however, how boundaries insist on separation. If Melissa breaks the boundaries between same-sex desire and friendship she risks total separation from Julietta. She would rather maintain enforced and accepted boundaries to remain safe and connected to Julietta.

The double is again established through the technique of incorporating handwriting styles that are distinct from the font used by the omniscient narrator. The first example of handwriting shows Julietta's script to be scrawly and scratchy, while Melissa's is rounded, careful and even (p.28). This is reinforced in Julietta's writing on her school book, where the style within the margins of her page has not changed, but in the picture of the heart, the style of writing becomes a composite of both Julietta's and Melissa's script (pp.73-74). Later in the text, when we see Melissa's handwritten diary, the style has completely changed. It has become Julietta's script, written by Melissa (pp. 98, 110$111,120,127-128,149)$. While the double is established, it relies on a connection between sameness and difference. As Jonathon Dollimore explains, 'difference...(is) the reordering of the already known, a disclosure of a radical interconnectedness which is the social, but which present cultures can rarely afford to acknowledge' (Dollimore 1991, p.230). This radical interconnectedness is represented by the double, which re-orders the proximity of sameness and difference and questions the split subject as a sequential stage in psychosexual development. This is seen through Julietta's worldliness and Melissa's jejunity being constructed alongside their shared but shifting subjectivity.

The imagery of the novel, too, maintains the doubleness of the characters. At Julietta's house, the girls sit between the two single beds 'cross-legged' (p.11), whilst at Melissa's home they sleep together in her single bed 'like spoons' (p.46). Although the characters are constructed as the double in the sense that they represent Lacan's desiring split subject, this is reordered in Camphor Laurel. Lacanian theory insists that the subject is split after the mirror stage. In Camphor Laurel the mirror stage occurs on the last page of text (p.157). Furthermore, contrary to Lacan's theories, the mirror phase in Camphor Laurel is shown to produce a wholeness through fulfillment of desire, rather than a subjectivity borne of lack: 'in front of her mirror, Melissa is more alive than she wants to be...she is on the edge of something in herself' (p.157). This occurs after her reunion with Julietta, so that it is through connection, rather than loss, that Melissa gains her subjectivity.

As McCallum notes, the doppelganger 'is a highly conventional narrative motif...used to explore a wide range of ideas related to personal maturation and the formation of subjectivity.... and the experience of subjectivity as fragmented, multiple and always in a state of becoming' (McCallum 1996, p.34). However, the use of the double can also be subversive of normative sexuality and the concept of 'maturation'. In Camphor Laurel the use of 
the doppelganger transposes many conventional ideas concerning sexuality in young girls - that psychosexual maturity relies on a confident sense of separation, that intense passions and desires are of a temporary nature, and language can define desire.

The text, in its open-endedness, subverts the notion that it is normal for adolescent girls to progress from 'crushes' on other girls (or same-sex desire) and that maturity brings with it a natural heterosexuality. Or that, further, even bisexuality can be typed, as Goggin attempts in his categories of 'real orientation', 'transitory orientation', 'transitional orientation', 'homosexual denial', etc. (Goggin 1993, p.106). As Halperin notes, though, '[queer] identity need not be grounded in any positive truth or in any stable reality' (Halperin 1995, p.62). Thus, although the characters may have appeared to mature, their unspecified sexual orientation at the conclusion of the text becomes unimportant in relation to the bonds of friendship and fulfilled desire, and no normative sexuality is endorsed. When the text creates the imagery of feminine bonds as more potent than (hetero) sexual desire: 'Their heads bend together... They reach for each other'(p.157), the Symbolic order is subverted, since these 'calm and pretty' girls communicate their desire and their pleasure without the use of language/narrative (p.157). This conception of desire, as disconnected from language, complicates Lacan's developmental model, and re-orders the concept of maturation.

It is in the conclusion of the text, too, that a rejection of the ordered world is instrumental in creating a space of positive connection. When Melissa confronts the mirror (stage) at the conclusion of the text, she feels beckoned by, and accepts, a notion of desire for the feminine 'inland ocean' within (p.157). Leaving her mirror, she embarks on her journey of accepting fluid desire by immersing herself in this space. She accepts rather than fears the 'swell [of] desire' (p.157) and thus opens up her subjectivity and sexuality to a fluidity. Describing three girls sitting beneath 'a shower' of camphor laurel leaves, the text recognises that two (characters) have become three - not the psychoanalytic triad of Lacan, but the 'becoming' of Deleuze.

Colebrook explains Deleuze's 'concept' in this way:

In order to really think and encounter life we need no longer see life in fixed and immobile terms. This means that thinking itself has had to become mobile and to free itself from the fixed foundations on man as subject.

(Colebrook 2002, p.xxi)

Man is displaced as the subject in this text. Man, as represented by the teacher, Mr. Upton, has been shown to bring truth and reason (and thus the ordered realm of the social) into question. This is represented in the text through the double of Melissa and Julietta in their relationship with Mr. Upton, which leads to a questioning of the 'truth' of experience; one that, as Dianna Fuss observes, can lead to a hierarchy of acceptance. Fuss asserts that this hierarchy, built on personal experience, enforces the exclusion of anyone who may not speak from that experience (Fuss 1989, pp.115-117). In Camphor Laurel, however, it is the combination of Julietta's experience, and Melissa's naïveté, that leads to a confrontation with truth through the narrative regarding Mr. Upton. Through the textual events that took place between Julietta and Mr. Upton, a deliberate ambiguity of meaning is maintained, and with it a questioning of any sense of truth. The text discusses the relationship as seduction, as fantasy and as molestation at different points, however it is through a reading which insists on linking sexuality to power that explains the limited subject positions available for young women in fiction.

Mr. Upton is constructed as young, attractive, white and middle-class. He is 'under thirty', and Julietta is sixteen. The construction of their relationship, then, has an age difference of, perhaps, fewer than ten years, and Julietta is shown to be over the age of sexual consent. Julietta also initiates both flirtation and a visit to Mr. Upton's home. This representation would not necessarily indicate molestation, except, however, in one crucial way: Mr. Upton is in a position of power and influence. He is representative of patriarchy (as father of a small child), and of authority (as teacher of history). His construction illustrates the power relations within discourse that underlie the heterosexual system regardless of age or maturity. Mr. Upton's narrative is accepted as truth, whilst Julietta's is displaced to fantasy. In this way, the textual events are open to subversion, since the text remains deliberately ambiguous regarding the events that occurred when Julietta visited Mr. Upton's home. This works to illustrate the assumptions we make 
regarding truth and power, in a cultural framework where the word, particularly in the discourse of psychoanalysis, constructs a male centre.

As the narrative progresses, Julietta denies that there was any sexual contact with Mr. Upton. Before this, however, Julietta demonstrated either the events, or her fantasy of them, to Melissa - a kiss, fondling her breasts (p.95). In this reconstruction, Julietta's erotic encounter is displaced onto Melissa. Yet this displacement is accepted as part of their friendship. The proximity of sexual desire and friendship becomes ever closer, blurring the boundaries between love, desire and sexuality, but also fantasy and reality. The physicality of Julietta's demonstration of events with Mr. Upton is the sharing of a secret, an accepted part of friendship, yet containing (very) proximate sexual desire.

Julietta's subsequent denial of events concerning $\mathrm{Mr}$. Upton's actions contradict the narrative. It is shown that Julietta spent half an hour inside Mr. Upton's home and that his car was in the driveway (p.94). Yet Mr. Upton denies that he was at the house, so Julietta's time in the house remains a silence. Following on from this, Mr. Upton frightens and upsets Julietta in his office. She leaves his (private) space trembling (p.97). Mr. Upton later calls Melissa into his office, to make the situation 'clear' (p.123). His 'ohso-careful hands' put things into place, and he states his facts of the day, ending with 'that's all' (p.124). Melissa does not speak; she nods, five times. She has no power in this masculine space where facts are not to be contested, where Symbolic language silences the feminine.

If one sees that Julietta had no choice but to lie about the events, however, then the episode between these characters becomes not one centered around sexuality and desire, but on how power works within the Symbolic order. The fictionalised account of molestation (both within Julietta's narrative and within the text) resonates with the material experience of many young women who are manipulated, threatened or frightened by an authority figure, so that they have no access to voicing any 'truth's they are silenced. This leads to the assertion that the Symbolic order disregards and disempowers feminine expression and, as Spargo illustrates in her analysis of Foucault, "the truth is not discovered, but rather produced” (Spargo 1999, p.14).
It is here, too, that we need to look at the workings of power within the discourse of development. Foucault explains that sexuality is not simply a given, but a category constructed within cultural, social, and historical frameworks. From this he illustrates how power networks, working through discourse, can be both regulating and potentially liberating. He resists 'natural' sexuality, and thereby undoes the ties that bind us to the ideas of normativity, shown as discursive constructs circulated through institutions such as the church, the state and medicine, including psychoanalysis (Foucault, 1978). 'Adolescence', 'young adult' or 'child' are categories that can mask hidden power relations, ones that are culturally contingent, and reinforced through discourses of development. Discourses of development, such as psychoanalysis, work to disempower young women.

These discourses reinforce adults' power to define and categorise what is acceptable and what is 'normal'. Young adults remain under the gaze of their elders, and as Foucault explains this leads to self-regulation and the disciplining of subjects into the categories that dominant discourses accept or reject (Foucault 1977). Conforming to a model of development with regard to sexuality enforces a degree of self-policing which restricts the possibilities for sexual diversity. The characters in Camphor Laurel display an awareness of how institutionalised discourses of adolescent sexuality create boundaries that are dangerous to break, when Melissa asks 'Do you think we're like in Heavenly Creatures?" (p.54). This intertextual reference is significant in several respects. It refers to a film (based on an event which occurred in New Zealand in the 50's - the ParkerHulme Case) that deals with intense passion and desire in young girls. This desire becomes so overwhelming (due to the girls' fear of separation), that they plan and carry out the murder of one of their mothers. It is not the murder, though, that is relevant in respect to Camphor Laurel, but the aftermath of it, where the discourse of the court system was wholly important in defining these girls, their actions, and thus their future.

The court's actions in the Parker-Hulme Case were influenced by the discourse of psychiatry. In defence of the girls, Dr Reginald Medicott commented on the evidence that the girls' illness was a folie à deux - a madness shared by two. Thus, the actual defendants in the case, Pauline 
and Juliet, were 'separate mouthpieces of a single delusive nature' (Knox 1995, p.680). The 'problem' with making a decision about the girls in/sanity in this case was the authorities' inability to define what constituted reality and fantasy. The girls' fantasies were said to have 'estranged them from the real world and alienated whatever vestiges of "natural" feminine compassion they possessed' (Knox 1995, p.680). Here, as Knox notes, the judgment, or the definition of these girls centers around their age, in regard to their relationship to fantasy, and to their gender, which had supposedly become 'unfeminine' due to the violence of the crime they committed. Without disregarding the severity of the crime, passion and fantasy, as part of young girls' lives, was disregarded by the court system, which privileged the 'truth' that the girls had entered an ordered realm, Lacan's Symbolic, and were capable of differentiating between fantasy and reality, and thus truth and fiction. Walker's text draws on this power of discourse to illustrate the dangers of refusing the Symbolic order of the patriarchal system. When Julietta hears Melissa's question 'Do you think we're like in Heavenly Creatures?' her 'head swings to Melissa's side; one eye half open. Or half closed'(p.54). Just as Julietta's eye position cannot be defined, Melissa refuses to be defined in terms of sexuality or desire and focuses on acts instead - ' I don't think I'd ever murder anyone' (p54).

This intertext sheds some light on the events which transpire between Julietta and Mr. Upton, demonstrating that they, too, enact a re-ordering of psychoanalytic theory. In order to gain subjectivity, a third (male) party, actual or imagined, must enter into the dyadic relationship between mother and child. This representative of the paternal then instigates the entry of the child into subjectivity and the Symbolic order through breaking the bonds of the feminine realm. Lacan regards 'the very normalisation of (this) maturation being henceforth dependent in man, on a cultural mediation as exemplified in the case of the sexual object, by the Oedipus complex' (Lacan 1966, p.7). Mr. Upton can be seen as this representative. However, rather than Mr. Upton's initiating a separation between Julietta and her double, he instead initiates, as we have seen, an erotic episode between Julietta and Melissa. When Julietta later flees, or separates, it is not Mr. Upton's intervention that has allowed her entry to the (adult) Symbolic order. It is, instead, Ursula who initiates a triad to allow subjectivity for Melissa. Melissa must accept Ursula, the 'barrier' to her relationship with Julietta (p.19). Yet Ursula is 'scary' and is responsible for Melissa's alienation from Julietta-the other of herself: 'Without Julietta, Melissa is no one' (p.120). However, Ursula also initiates an understanding in Melissa, one that allows her to become agent, and position herself differently, since Ursula, also 'has a theory' (p.145), one that perceives Melissa and Julietta's relationship differently. Melissa and Ursula now become 'the other half of each other' (p.148), a strength of feminine bonds that are the precursor to the new relationship between the three girls. It is the feminine, then, that initiates subjectivity, not the intrusion by a real or imagined representative of phallic power.

The Symbolic order in Camphor Laurel is both recognised and de-legitimised within the text's representation of reality. Subjectivity relies, now, on feminine bonds and connections. The text provides a metaphor for the threat to the Symbolic order of feminine same-sex desire in the use of the Camphor Laurel tree. This tree seems to represent feminine desire; it is unable to be contained and is a threat to order: 'the path...is broken up by Camphor Laurel roots...for blocks down the hill, the cement is cracked, up-lifted, tarred over, sagging and destroyed' (p.138). The potential satisfactions of feminine desire are equally encapsulated in the following metaphor: 'she imagines the hill as it could have been - a round, tall, happy green hill where trees don't struggle to breathe' (p.138). It is relevant to consider here how the camphor laurel tree is now recognised as a fearful strength. If we frame the definition of this class of tree within a metaphorical context of feminine desire, it has much to say about the threat of the feminine: camphor laurel has now become an exotic pest, a noxious weed that is causing disruption to the native species. Feminine desire, then, cannot be accounted for through lack and alienation, but through bonds and connections. It cannot be categorised neatly in friendship, sexual taxonomies or discourses that allow masculinity to remain central. It is the threat of 'other' to the 'native species' of the long entrenched phallic order.

McCallum's assertion, as discussed previously, that Lacanian theory and the use of the doppelganger in fiction allows readings of constructed subjectivity, is now linked to an 
element of the essential in the imagery of the camphor laurel tree and its metaphorical relationship to the girls' desires. We see a discussion of such relationships in the theories of Fuss, who implicates essentialism in constructionism, and illustrates the dependency and proximity of the one to the other. As Fuss notes, there are potentialities and dangers of an either/or position, which are both informed by the other (Fuss, 1989). The other of essentialism finds its way, here, into the constructivist theories of Lacanian subjectivity. The other always remains within.

In its techniques of the use of shifting and slippery language, its intertextuality in the use of diaries and invocation of the film 'Heavenly Creatures', and in its prose which blurs the boundaries between the poetic, the scientific (in the use of the Encarta definition), and fantasy, Camphor Laurel plays out as a text that is reminiscent of a portrayal of the unconscious itself. There is, however, a repositioning, or a reordering of Lacanian psychoanalytic discourse. The split subject, represented by the doppelganger, is positioned prior to the mirror stage. The mirror stage leads to subjectivity through connection rather than separation, lack is replaced with fulfillment, and desire is legitimated within the feminine realm: 'the madness of telling' (p13), which so excites Melissa and Julietta, reminds us that it is in the telling that posits the subject as mad/sane, normal/abnormal within psychoanalytic and medical discourse which, as Foucault reminds us, replaces the confessional in secular times (Foucault 1978, p.63).

Walker's text offers a resistance to conventional categorisations of desire. The narrative does not progress through an inversion of binaries to a collapse of them, but rather, begins at the point of fusion between binary opposites. Nor is the essentialist/constructivist debate allowed to escape scrutiny. Instead, the identity binary dissolves within the imagery of a desire where (Symbolic) language is not merely inadequate, but is guided, instead, by a narrative of celebration rather than lack. Western theories of maturation, of subjectivity within the phallic order and of sexuality in the young adult are all reorganised in Camphor Laurel and work to counteract the lack of representation of girls' desire and passion, and to contest the acceptance of the Symbolic ordered world which silences these desires. We are reminded by the text of Camphor Laurel, too, that with any theory, particularly those devised by men, and produced to discuss feminine desire, 'There's no way to check this hot-afternoon philosophy' (p.15).

\section{REFERENCES}

Colebrook, Claire (2002) Understanding Deleuze. Crows Nest, Australia, Allen \& Unwin.

Deleuze, Gilles and Guattari, Felix (1988) A Thousand Plateaus: Capitalism \& Schizophrenia. London, The Athlone Press.

Dollimore, Jonathon (1991) Sexual Dissidence, Augustine to Wilde, Freud to Foucault. Oxford, Clarendon Press.

Foucault, Michel (1979) Discipline and Punish: The Birth of the Prison. New York, Vintage.

Foucault, Michel [1978] (1990) The History of Sexuality: An Introduction. Volume 1. New York, Random House, Vintage edition.

Fuss, Dianna (ed) (1989) Essentially Speaking: Feminism Nature and Difference. New York, Routledge.

Goggin, Mark (1993) 'Gay and lesbian adolescence', in S. Moore and D. Rosenthal (eds) Sexuality in Adolescence. London, Routledge.

Halperin, David (1995) St Foucault. Towards a Gay Hagiography. New York and Oxford, Oxford University Press.

Knox, Sara (1995) 'Heavenly games', Meanjin 54: 4: 677-690.

Lacan, Jacques [1966] (1977) Ecrits. A Selection, Translated by Alan Sheridan. London, 
Routledge Edition.

McCallum, Robyn (1996) 'Other selves: subjectivity and the doppelganger in Australian adolescent fiction', in Clare Bradford (ed) Writing the Australian Child. Nedlands, Western Australia, University of Western Australia Press, pp. 17-36.

McCallum, Robyn. (1999) Ideologies of Identity in Adolescent Fiction: the Dialogic Construction of Subjectivity. New York, Garland.

Rowley, Hazel and Grosz, Elizabeth (1990)

'Psychoanalysis and feminism', in Sneja Gunew (ed) Feminist Knowledge: Critique and Construct. London, Routledge, pp. 175-204.

Spargo, Tasmin (1999) Foucault and Queer Theory. London, Icon Books.

Walker, Sarah (1998) Camphor Laurel. Sydney, Pan Macmillan.
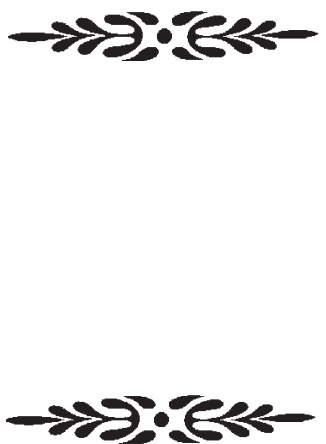

\section{ACKNOWLEDGEMENT}

Kate McInally would like to acknowledge the support of Dr Elizabeth Parsons, lecturer at Deakin University, in the writing of this article.

\section{BIOGRAPHICAL NOTE}

Kate McInally is currently researching and teaching children's literature at Deakin University. Her particular interests are contemporary Australian young adult fiction and queer theory. 